discharge. The doctor is not, therefore, an autocrat on the bridge handing down commands to all around her.

If this is true, then it may be dangerous for the doctor to step out of this individual role and influence the medical care of groups of patients, because there will be conflict between, say, keeping his patient in hospital and pressures to shorten the average length of stay in hospital. Politicians forget that it is only too easy to practise cheap medicine, but that this may not be right.

The third relationship discussed in this book is that beiween the doctor and litigation over his actions. Many doctors believe that the increasingly vexatious patient will damage the trust between patients and their doctors and that this will impair standards of medical care. More legal action will force doctors to reconsider whether the risks to them (sic) justify carrying out potentially dangerous procedures. They can always decline to do so, and instead ask the patient to seek another opinion. Who benefits then?

Naturally there are no answers in this book, but I recommend practising doctors, and not just those interested in philosophy and ethics, to read this book. I found that some of the writing was neither simple nor clear and some words should not have been allowed to escape from the dictionaries. But this writing on the hospital walls should not be ignored by the profession.

R P H THOMPSON Consultant Physician St Thomas's Hospital London SE1 $7 E H$

\section{Explorations in Medicine: Volume 1}

\section{Edited by David Lamb, Teifion}

Davies, and Marie Roberts, 222 pages, Aldershot, £22.50, Gower Publishing Group, 1987

A major issue in contemporary philosophy of medicine is that of mechanism versus holism. In a mechanistic approach, the essential subject of medical theory is how the operation of physical processes results in functioning and malfunctioning of the various bodily organs; health is defined as the absence of disease, illness or injury; and the task of medicine is to relieve malfunctioning and suffering by removing its physical causes. In a holistic approach, the subject is the person as a whole, health is an ideal of maximum well-being and the function of medicine is not only to relieve injury and pain but also to increase personal autonomy. A crucial question for both theory and practice is which approach should be adopted, or, if they are combined, how exactly the synthesis is to be made.

The articles in this collection cover a range of topics in medical ethics and philosophy of medicine, but they have in common that they all to some degree defend or presuppose a holistic and person-centred approach to medicine. This is most explicit in the two papers by $\mathrm{E} \mathrm{K} \mathrm{Ledermann,} \mathrm{the} \mathrm{first} \mathrm{of} \mathrm{which}$ argues that, while both approaches must be used, the holistic approach should be primary, while the second reinforces the point by showing how theories in medicine differ significantly from those in the purely physical sciences, such as astronomy. These papers are complemented by David Seedhouse's, which argues for a holistic concept of health, and by Ann Slack's, which describes some of the harm done by the excessively mechanistic approach of the 'medical establishment'.

Three other papers show, by implication, the need for a holistic approach to medical ethics, ie one that both respects individuals as persons and acknowledges that they are members of a wider social group. Thus Ruth Chadwick's paper criticises the Warnock Report for trying to deal with the ethics of reproductive technology without considering its effects on society as a whole. George Agich's paper argues that there are great difficulties in deciding what is a justifiable policy for genetic engineering if one relies on traditional or 'Rawlsian' considerations of justice (though it is unclear whether his conclusion is that we should reject genetic engineering altogether or that we should use a less individualistic ethical framework). And Bob Brecher seeks to demonstrate the impossibility of any morally neutral definition of mental illness, such as one based on lack of 'rationality', from which it would follow that even diagnosis has to consider the person in society.

The remaining three papers are concerned with applying the moral principle of respect for persons. Charles Dougherty derives from it ten criteria for 'morally acceptable research with human subjects', many of which have been all too often ignored. Heather Milne derives from 'a view of persons as "moral wholes"' a theory of the limits of permissible genetic engineering.
Finally, David Lamb examines 'the slippery slope' argument, that to permit abortion or to legalise euthanasia, even in limited and justifiable instances, would erode respect for human life, and argues that it fails in the case of abortion but is valid for euthanasia.

It should be added that the level of these papers is very high. Some are more concise than others, but every one of them is clear, interesting and worth reading. No reader is likely to agree with everything in them; but something can be learnt from them all.

HARRY LESSER Lecturer in Philosophy Dept of Philosophy, University of Manchester

\section{The Contraceptive Ethos: Reproductive Rights and Responsibilities}

Edited by Stuart F Spicker, William B Bondeson and $\mathrm{H}$ Tristram Engelhardt $\mathrm{Jr}, 254$ pages, Dordrecht, Holland, $£ 32.95$, US \$39, DF1 120.00, D Reidel Publishing Company, 1987

This book, part of a series on philosophy and medicine, contains thirteen papers presented at an American symposium entitled Reproductive Rights and Responsibilities: Medicine and the New Biology, held in 1983, and subsequently revised after discussion between authors and participants. The authors are American, mainly academics in medicine, philosophy, law, political science, sociology, history and population dynamics.

The book's introduction refers to 'the plethora of concepts germane to the new contraceptive ethos'. Some of the authors, however, question whether modern contraceptive technology has led to a new ethos about procreation, contraception, parenthood and population. This key question evokes a variety of responses. Most of the authors agree that sexual activity and contraception have to be seen in their social and moral context. The development of effective contraception has depended on contemporary cultural determinants, especially sexual attitudes and the socio-economic role of the female. Other factors influencing sexual behaviours are general population need, maternal and infant mortality rates, beliefs about 